\title{
Achieving Change in Student Assessment Policies and Practices: A Pressing Challenge FOR ViETNAM's Higher EdUCATION SYSTEM
}

\author{
Luong Thi Hong Gama \\ Thu Dau Mot University \\ Sharon Parry \\ Southern Cross University \\ Martin Hayden \\ Southern Cross University
}

\begin{abstract}
Within Vietnam's higher education system, traditional norm-referenced approaches to student assessment continue to be widely adopted. Though the system is progressively being reformed with a view to achieving comparability with leading higher education systems globally, student assessment policies and practices have so far proven to be resistant to change. This article addresses the challenge of achieving change in these policies and practices. It is informed by an ethnographic investigation of experiences with student assessment for a selected sample group of academic staff members at three significant teacher training universities in Vietnam. A framework for achieving change is proposed in light of these experiences and having regard to insights from the relevant conceptual literature.
\end{abstract}

Keywords: higher education, student assessment, formative assessment, educational change, teacher training institutions, Vietnam

\section{Introduction}

The quality of student assessment is pivotal to the quality of a higher education system. As Rowntree (1977, p. 1) perceptively observed: "If we wish to discover the truth about an educational system, we must look into its [student] assessment procedures." In Vietnam, higher education institutions continue predominantly to adopt traditional student assessment practices (Nguyen Thi Hong Tham, 2013; Tran Thi Tuyet, 2013, 2015; Ho Thi Nhat, 2015). These practices are driven by a perceived need to rank cohorts of students in terms of their academic performance, usually by requiring them to undertake stressful summative tests and examinations.

Most developed higher education systems have moved beyond these practices. A significant influence in this regard has been research which began to be reported in the early 1980s concerning the extent to which students adopt different approaches to learning in response to different approaches to student assessment (see, for example, Marton, Hounsell and Entwistle, 1984; Biggs and Collis, 1982). Norm-referenced approaches to student assessment, that is, using assessment processes largely or solely for the purposes of ranking students in terms of their relative performance on summative tests and examinations, have been shown to contribute to surface forms of learning, as distinct from learning focused upon achieving a deep understanding of curriculum content and a strong sense of personal engagement with the learning process (Biggs and Tang, 2007, p. 22). Normreferenced approaches have also been shown to contribute to the perpetuation of entrenched social and educational inequities (Morgan, Dunn, Parry and O'Reilly, 2004, pp. 22-24).

\footnotetext{
Correspondence can be directed to: gamlth@tdmu.edu.vn
} 
A popular alternative to norm-referenced student assessment is a standards-based approach. Standards-based student assessment requires students to be informed in advance about the standards of attainment associated with different grade levels of achievement in a unit of study (Morgan et al., 2004, pp. 26-29). Student assessment is then focused upon providing the students with opportunities to demonstrate the extent of their success in attaining these standards. This approach to student assessment is highly conducive to the adoption of formative assessment procedures, whereby student achievements are assessed for the purposes of providing feedback to students about their progress with learning. Formative assessment, which encourages a much greater reliance upon self-directed approaches to learning, has been convincingly shown by Black and Wiliam (1998a, 1998b) to contribute to the quality of student learning to a far greater extent than does summative assessment.

Vietnam's slowness in adopting an alternative to summative and norm-referenced approaches to student assessment has been the subject of ongoing discussion in the scholarly literature on teaching and learning in Vietnam. A likely explanation is that most lecturers, academic managers and government officials are relatively unfamiliar with anything other than summative examinations and norm-referencing (Institute for Educational Research, 2005; Ho Thi Nhat, 2015; Luong, 2016). It is also likely that there are limited opportunities available in Vietnam for lecturers and academic managers to discuss alternatives to summative assessment and norm-referencing because there are relatively limited opportunities of participation in professional development programs where different approaches to students assessment might be freely discussed and debated (Nguyen Thi Hong Tham, 2013). Higher education lecturers are also very poorly paid and often need to supplement their income by engaging in extra teaching duties, which leave little time for engaging in innovation with teaching and student assessment (Le Thi Kim Anh and Hayden, 2017).

This paper addresses the question of how to achieve change in the policies and practices applying to student assessment in Vietnam's higher education system. Its specific purpose is to identify the conditions needing to be addressed for the purposes of introducing more contemporary approaches to student assessment. This topic is important because not only is the norm-referenced student assessment culture in Vietnam becoming increasingly anachronistic by world standards, but it is also a culture which gives rise to excessively high levels of student stress and, potentially, unfair grading practices.

In recognition of the extent of the stress imposed on students by end-of-unit summative examinations, Vietnam's Ministry of Education and Training (MOET) in 2007 issued a directive (MOET, 2007) requiring the introduction of continuous assessment processes within units of study. This directive did not, however, address the underlying problem of the system's preoccupation with summative assessment and norm-referencing. The directive achieved little more than to increase the number of summative assessment tasks having to be completed by students while completing a unit of study.

\section{How to Achieve Educational Change}

There is a substantial body of literature available about the nature of and pre-conditions for educational change. Fullan's (2001) theory of educational change, which gives expression to ideas based upon complexity theory, tends to dominate this literature. The following account begins with a brief overview of complexity theory, and then introduces key propositions from Fullan's theory.

Complexity theory applies to social organisations. These organisations are conceptualised as being in a state of continuous change, driven by forces from within as well as from outside the organisation. These forces derive from interactions occurring within and between organisations as individuals and groups, referred to as agents, seek to achieve their personal goals while at the same time contributing to the organisation's need to achieve its goals (Stacey, 1995; 1996; 2007; Tosey, 2002). Certain principles and rules, termed schemas, impose a measure of orderliness on the nature of these interactions, but these schemas may be transformed if the prevailing culture of either the 
organisation itself or the organisation's external environment undergoes change. Change involves, therefore, the emergence of new schemas which in turn affect patterns of behaviour within the organisation. The process whereby schemas are transformed is said to be relatively unpredictable in nature and to seldom occur in a linear manner. According to complexity theory, achieving change in the prevailing schema concerning student assessment would involve the application of pressure from within or from outside the organisation to achieve the adoption of new patterns of behaviour concerning student assessment. Until all agents in the organisation have accepted the overall value of the new schema, enduring change cannot be said to have occurred.

Drawing on complexity theory, Fullan (2001, p. 44) argued that meaningful educational change required 'reculturing', a process which he said involved challenging people's beliefs, values and ways of thinking with a view to advancing better-informed practices. He argued (2007, pp. 88-9) that significant cultural change was more likely to occur in circumstances where the need for change was clearly understood, and where the individuals concerned were well informed about how it could be achieved.

Educational change, in his view, also required a certain kind of leadership. Leaders of change had to be 'context setters' (Fullan, 2001, pp. 112-115), capable of explaining the need for change and of guiding members of a community through the processes of change. Fullan referred to these leaders as needing to have "change knowledge", defined as "understanding and insight about the process of change and the key drivers" (Fullan et al., 2005, p. 54-8). These drivers were identified as including a moral purpose; a transparent and coherent change process; and a culture of progressive evaluation towards achieving outcomes.

Fullan's theory resonates in many respects with Lave and Wenger's (1991) view of educational organisations as socio-semiotic communities of practice within which meanings are constructed by community members through interaction with one another. Wenger (1998a, p. 45) described communities of practice as social groupings "created over time by the sustained pursuit of a shared enterprise". Engaging in these communities was said to enable members to exchange both explicit and tacit knowledge related to their shared enterprise, and to learn from these exchanges, thereby providing the foundations for the development of a capacity for future change (see also Wenger, 1998a; Wenger and Snyder, 2000; Wenger, McDermott and Snyder, 2002).

\section{Methodology}

To obtain empirical insights regarding the existing state of change in the culture of student assessment in Vietnam's higher education system, in-depth interviews were conducted with a selected sample group of academic staff members from across three significant teacher training universities. Teacher training universities are highly influential in Vietnam in terms of their influence on approaches to teaching and learning across the higher education system. The three site institutions included one each in Hanoi and Ho Chi Minh City (HCMC), and one located on the outskirts of HCMC.

The investigation was implemented following the precepts of Naturalistic Inquiry (Lincoln \& Guba, 1985), which requires that data should be collected and analysed in tandem using ethnographic techniques and in a way which does not intrude on the natural setting of the participants. In addition, Naturalistic Inquiry holds strongly to a view that findings generated in this way must be trustworthy, and it proposes various methods for assuring this trustworthiness.

The participants in the investigation were selected by means of a 'snowball' sampling procedure, as described by Patton (2002, p. 237). To initiate the process, several lecturers known to one of the authors to be highly experienced with student assessment practices and to be open-minded about the need for assessment reform were selected from across each of the three site institutions. These participants then nominated colleagues who were also experienced with student assessment and who might be interesting to interview from the point of view of learning about pressures for the reform of student assessment practices within the higher education system. 
Semi-structured interviews were conducted with 24 participants before data saturation and redundancy began to increase. These participants were nearly all interviewed several times. They were also observed at length in the settings in which they worked. The interviews were guided by Spradley's (1979) account of the nature of ethnographic interviewing. The interview schedule (see Appendix A) included nine leading questions, each addressing a different aspect of the culture of student assessment at whichever of the three site institutions was concerned. These questions probed the beliefs, values and attitudes of the participants regarding student assessment. The interviews were conducted in Vietnamese by one of the authors. There was in addition a vigorous examination conducted of relevant documentary sources, including course outlines, current assessment tasks and relevant institutional student assessment policies.

Thematic analysis of the interview data using Glaser and Strauss' (1967) constant comparative method was employed to identify emergent themes. The software package, Nvivo*9, assisted with data management and retrieval.

Trustworthiness, which was a vital element in the research design, was achieved by implementing specific strategies recommended by Lincoln and Guba (1985, p. 301), including multiple types of triangulation, prolonged engagement, peer debriefing, member checking, 'thick' description, the use of a reflexive journal, and the execution of an audit trail, which was checked and verified by an independent auditor. Before conducting the interviews, all participants were informed that the data collected would be handled confidentially, and that pseudonyms would be employed when reporting the findings.

\section{Findings}

From the large volume of data collected, three categories of participants could be readily identified. The participants in two of these categories, accounting for 21 of the 24 participants, were, as expected, clearly reform-minded with respect student assessment policies and practices. However, three other participants were not at all reform-minded, and argued strongly for the retention of norm-referencing. Given that it had been anticipated that all participants selected would be open to reform regarding student assessment in Vietnam's higher education system, it was surprising that these three participants were identified. Instead of excluding them from the data set, they were included, thereby providing a sample sub-group which yielded valuable insights regarding the beliefs, values and attitudes of academic staff members in Vietnam who were committed to a continuing reliance upon summative examinations and norm-referencing in determining grade levels for student performance in units of study.

Three distinct categories of participants were identified from the findings and are labelled as Adaptive Implementers (8 participants), Changing Pragmatists (13 participants) and Defending Denialists (3 participants). The defining features of these three categories are now reported.

\section{Adaptive Implementers}

The eight participants who were Adaptive Implementers not only believed in the need to break away from norm-referenced assessment but were also responsible for having introduced formative assessment tasks in the units for which they were responsible. One of these participants reported how, for example:

I make comments on the overall quality of the students' work, what they need to improve, and I provide suggestions for improvement. Each group is then required to reflect on their learning and to adjust their projects based on feedback provided. (Hong) 
Another reported that:

To encourage students in asking questions and sharing their ideas, I [encourage] group discussions, and then each group presents its results. After each group finishes its presentation, I require other groups to ask questions. Finally, I provide each group with constructive feedback. (Huyen)

Implicit here was a belief that student learning became qualitatively richer when students were required to learn from constructive feedback, and when they were required to engage with learning materials by asking questions and by sharing points of view. This belief was widely shared among the Adaptive Implementers.

The Adaptive Implementers routinely implemented formative assessment practices on a purely voluntary basis, with no formal or departmental recognition, or time allocation, provided for what they were doing. They reported, however, that their colleagues were generally respectful of what they were doing. From their point of view, though, the culture in which they worked was dominated by summative and norm-referenced approaches to student assessment, and they knew well that when submitting final grades for their students they were also required to arrive at a distribution of grades that would correspond with acceptable norms within their faculties.

They expressed a great deal of frustration that MOET, having sensibly decided in 2007 to require that end-of-unit examinations should not be solely relied upon to determine final grades in units, had made no further policy progress in terms of modernising higher education student assessment policies and practices in Vietnam. One of the participants stated, for example:

It is nearly ten years since the [MoET] Decisions were issued. There has been no follow-up to see what more needs to be done, no evaluation, and no sense of seeing how assessment has evolved or developed. Thus, change happens only at the level of the individual lecturer. (Hong)

Implementing formative assessment procedures was uniformly reported by the Adaptive Implementers to require more time than did the conduct of summative assessment procedures. For this reason alone, it was said to be difficult to persuade colleagues to engage more with formative approaches to student assessment. One of the Adaptive Implementers, who was an academic manager, explained the difficulty he had in persuading more of his colleagues to adopt formative assessment:

... because of the low salary and the shortage of financial incentives, whenever I raise this issue [of implementing formative assessment], my staff always ask me 'will we be paid [more] for doing this job?' So I am only able to encourage those who are interested and enthusiastic in making change [by themselves]. (Luc)

He considered that, in general, MOET appeared to have little interest in encouraging more experimentation with approaches to student assessment, and individual higher education institutions also showed little interest improving the quality of student assessment practices. It was of concern to him that individual lecturers who were experimenting with more enlightened approaches to student assessment were being left to do so at high personal cost because they were foregoing opportunities to earn additional income by taking on extra teaching duties.

\section{Changing Pragmatists}

The 13 Changing Pragmatists also argued for the need to break away from a reliance on summative examinations and norm-referencing, but mostly they had not done so consistently or effectively because they regarded the obstacles to making this change as being too onerous. For some of these participants, there was a realisation that formative student assessment required more time 
to implement, and they felt that they did not have any spare time, given the pressure on them to supplement their incomes by doing additional teaching. A typical comment was:

I teach an average of 16 to 20 hours per week. There are also too many students in a classroom [50 to 60 students], and the training curriculum is heavy in theoretical knowledge. ... I should [be carefully providing] students with timely feedback on their performance. However, with these constraints, I am unable to carry out this function well. (My)

Low salaries were referred to by nearly all of these participants as leaving them with no time for anything other than the routine use of summative tests and examinations. As another Changing Pragmatist explained:

The payment for one teaching period is approximately 50,000 to 60,000 VND ( $\$ 2.5$ to $\$ 3$ USD) per hour. If a teaching unit includes 30 teaching hours, I will receive about $1,500,000$ VND (\$75 USD). If I spend a great deal of time marking and providing formative feedback, I will need to sacrifice my other jobs. I regret that although I know the need to change my student assessment practices, I have not yet done as much as I would like. (Vuong)

Though genuinely concerned about the deficiencies they perceived in the dominant student assessment practices adopted at their university, the realities of life for them as academics were seen to render active engagement with formative assessment approaches to be completely impractical. A large proportion of these Changing Pragmatists referred to the tension between supporting their families and implementing sufficient formative assessment to encourage deep learning among their students.

More than one-half of the Changing Pragmatists also expressed a lack of confidence about using formative assessment. One explained, for example that: "I simply do not have enough understanding about [formative] student assessment" (Duyen). Others referred to a need for more professional development to assist them to understand better the nature of standards-based and formative assessment approaches. They expressed disappointment about the lack of professional development opportunities available to academic staff members generally. One participant reported, for example: "During the past five years, I have had no opportunities to attend training courses [about student assessment]" (Xuan). Those few who had attended training courses on student assessment reported that the insights obtained were not always welcomed within their departments. One participant explained, for example: "My head of department ... neither encourages me to implement these practices nor to share them with my colleagues" (Vuong). This participant also reported that: "The educational leaders do not create an environment where lecturers . . can share experiences and learn from each other. ... There is a lack of professional dialogue amongst lecturers" (Vuong).

The context for this and many similar comments was a tacit understanding that the management culture in Vietnamese universities was 'top-down' in terms of the exercise of control. As one participant reported: "I see that the head of department and university leaders expect their staff to listen and implement their orders. Opposing ideas or opinions are often excluded" (Duyen). This situation meant that any significant institution-wide change to assessment policies and practices in Vietnam's higher education system were most unlikely to occur until sanctioned by senior university managers.

\section{Defending Denialists}

As noted earlier, the three Defending Denialists expressed a strong commitment to retaining summative examinations and norm-referencing. They regarded norm-referencing as a procedure which provided all stakeholders in university education with critical information about the academic performance of students relative to one another. Norm-referencing was also seen as being simple to 
implement, particularly if members of staff made use of multiple-choice and short essay questions. Standardised multiple-choice tests appealed to them because, as one of the participants reported: "I use objective tests because I believe that I can assess all students fairly and comprehensively regarding all the knowledge that I transferred to my students [in classes]" (Tran). Another reported that he recognised the emotional pressure on students due to implementing only summative approaches to assessment, but he remained convinced of the effectiveness of summative examinations for assessing student abilities: "I agree [that] exams focus more on factual knowledge but I think examinations are necessary to sort out which students should not be doing that subject" (Quyet). Absent altogether among this sub-group was any concern about students' independent learning or problem-solving capacity.

\section{Shifting a Culture}

The Adaptive Implementers and Changing Pragmatists provided numerous suggestions for ways in which Vietnam's higher education system could be shifted from being dominated by a 'testing culture', as opposed to a 'learning culture' (Shepard, 2000, pp. 1-3). Implicit in many of these suggestions was a perceived need for a more informed leadership, nationally as well as institutionally. As one of the participants, who was himself an academic manager, stated:

It is important for administrative leaders and academic managers at all management levels to understand the necessity of change towards formative assessment. More importantly, they should realise that change towards different purposes of student assessment is inevitable. (Luc)

A sense of the inevitability of change underscored many of the views expressed by both Adaptive Implementers and Changing Pragmatists. In general, they believed that the higher education system in Vietnam could not hold out for much longer in terms of its reliance on norm-referencing. Though in many cases unfamiliar with how alternative student assessment approaches, such as standardsbased assessment, work, they considered that academic staff members in Vietnam needed to prepare for a time when norm-referencing as an approach to student assessment would be discarded as inequitable and prone to eliciting only surface approaches to learning, as Black and Wiliam (1998a, 1998b) identified. One of the Adaptive Implementers commented, for example:

It is time for us to cooperate and develop our teaching and assessment activities together for the benefit of our students. That would be a good way to broaden the implementation of effective assessment. (Tuan)

In this vein, MOET was seen to be proceeding far too slowly with the provision of either a vision for the future of higher education student assessment practice and with the concomitant professional development needed by lecturers and academic managers.

There was also a widely shared view that universities needed to develop their own student assessment policies, and that they begin to do so by supporting lecturers and academic managers to develop the skills and understanding required for the adoption of new approaches to student assessment once they are approved by MOET. A representative argument was:

University assessment policy should state all the requirements, and outline the procedures for different purposes of student assessment. This policy should also provide a coherent statement of what the institution is trying to achieve. (Trung)

This participant went on to explain that if an institution's assessment policy clearly articulated requirements for change, and if it provided well-informed guidelines for implementing change, then lecturers would be much more able to transition to a new approach to student assessment practice. 
Changing the culture of student assessment was seen, however, as only one part of a much broader suite of changes required for the purposes of shifting the culture of higher education in Vietnam. The large majority of Adaptive Implementers and Changing Pragmatists reported feeling professionally constrained by their meagre salary levels, which necessitated the acceptance of extra teaching duties or outside work for the sake of supplementing family incomes. They also commented on the extent to which poor working conditions and the lack of adequate teaching resources were personally demotivating. One of these participants stated, for example:

There must be a fundamental change in the support system for lecturers, such as reducing the amount of [emphasis on] theoretical knowledge and [changing the] overloaded curriculum [by] reducing the teaching hours and [improving the] student/lecturer ratio, and upgrading the teaching facilities, working conditions and the means for assessment. (Tien)

Another commented along similar lines:

If sufficient salaries for lecturers are secured, lecturers [will] not have to struggle doing the second or the third jobs. Lecturers may [then] concentrate to make [these time-consuming] change because this is their duty. (Luc)

In general, shifting the culture of student assessment in Vietnam's higher education was seen as forming one part of an even bigger need to shift the culture of support for academic staff members by supporting more learner-centred approaches to teaching. This requires: increasing salaries; improving the staff-to-student ratio; providing improved teaching facilities; and enabling lecturers to participate more fully in professional development opportunities.

\section{Implications}

The findings reported above give rise to a number of implications. First, most participants regarded student assessment as an integral part of the teaching process and also an important driver of the quality of student learning. Their views mirrored insights reported by Marton et al. (1984) and by Biggs (1996), amongst others. Most of the participants also recognised the potential of formative assessment to motivate students to engage more deeply with their studies by using 'deeper' approaches to learning, as described by Marton et al. (1984), and many others over almost four decades. In most cases, the participants were genuinely interested in adopting approaches to learning that focused less on simply ranking student performance and more on encouraging students to become more self-directed with their learning. In this vein, Nguyen Thi Hong Tham (2013) and Ho Thi Nhat (2015) have also reported that lecturers in higher education institutions in Vietnam are open to explore alternatives to the present regime of reliance on summative examinations. To date, however, the commitment to achieve change has been an individual rather than a system-wide choice and responsibility. In a complex adaptive system, as described by Stacey (1995) and Fullan (2007), the commitment of individuals to change is not likely to be sufficient to achieve deep and meaningful system-wide change. There must also be a whole-of-system commitment to change, which means a change in the values and commitments of an entire community of practice.

Second, MOET has overall responsibility for curriculum matters in Vietnam. Leadership in any change process needs to be initiated, supported and reinforced by MOET if widespread cultural change is to occur. The Adaptive Implementers and Changing Pragmatists, whilst eager for change, were very much aware that system-wide change needed MOET to provide clear and consistent leadership and direction. This perspective resonated with Fullan's emphasis on the essential role of government in achieving whole-of-system educational change. He regarded government as "a major force for transformation" (Fullan, 2007, p. 236). If, however, MOET, together with university leaders, are not convinced of the wisdom of the better research-informed approaches to student assessment, then the likelihood of their widespread adoption in Vietnam's higher education system can only remain restricted. At present, the national student assessment regulations require higher 
education institutions to ensure that each student's performance is graded on a 10-point scale in every unit of study delivered. This requirement reportedly forced the participants, even the Adaptive Implementers, to grade their students in a way that reflected a rank, or cohort-referenced, order of merit. The Adaptive Implementers found this requirement difficult to reconcile with their commitment to formative assessment and with a reliance on the professional judgement of lecturers in assessing student performance. For most other participants, the requirement also raised questions about the intent of the MOET's policy statement in 2007 concerning student assessment, because the regulations issued by the MOET were not supported by protocols for how the regulations might be implemented. Fullan (2007, p. 87) describes this kind of a situation as one in which there is an incomplete understanding of the deeper underlying reasons why significant educational change is needed in an organisation such as a university, arguing that when an organisation has a clear vision, underpinned by a clear set of values and a singular purpose, then that vision permeates the organization, providing the 'moral purpose' for enduring educational change.

Third, clearly the time is ripe for MOET to articulate a vision for the future of student assessment across Vietnam's higher education system. Ideally, this vision commits the system to more learnercentred approaches to student assessment, such as through the use of standards-based and formative assessment practices. Individual higher education institutions would then be obliged to produce coherent statements about the assessment procedures they endorse, together with clear guidance for the implementation of these procedures. Further, MOET would need to acknowledge the amount of time it takes to implement more effective student assessment procedures, and so teachers would need to be remunerated and reviewed, with annual performance review and development requirements instituted, accordingly. The challenge MOET faces is huge. Other national systems have taken decades of wrangling with the different dimensions of the same kind of challenge. Hopefully, effective change will not take as long to be achieved in Vietnam where the lessons of several decades can be assimilated without a trial-and-error form of learning.

A commitment to the professional development of academic staff members across the Vietnamese higher education system is also required for such an important evolution in teaching, learning and assessment practices. Most of the participants in the investigation reported that their experiences of professional development regarding the adoption of new approaches to student assessment had been inadequate, or, more widely, non-existent. In the case of the Changing Pragmatists, the absence of professional development was reported to have influenced their decision to remain locked into summative assessment practices, even though they were not comfortable with them. Professional development activities provided to date by MOET reportedly fell well short of the expressed needs of the participants concerning the need for information about new approaches to student assessment. In this regard, both Goldenberg and Gallimore (1991), and Mouza (2002), have reported on the limited utility of short training programs in providing ongoing support for long-term change processes. In the same vein, Kane and Khattri (1995) reported that educators cannot be expected to incorporate new formative assessment practices in their teaching without the support of lengthy and intensive professional development programs. It is essential, therefore, that teacher training universities in Vietnam should have their own well-planned and on-going systems for the professional development of lecturers and academic managers. Kane and Khattri (1995) suggested that such programs need to help lecturers to know how to design assessment tasks, how to design rubrics, how to set up student performance standards and how to provide constructive feedback to students.

Many Changing Pragmatists reported that they did not feel well supported by their education managers to vary their assessment practices. These participants did not sense opportunities for "learning in context", as described by Fullan et al. (2005, p. 58). Wenger (1998b) argued that academic settings are communities of practice in which negotiation, exchange and collaboration are essential for change to happen. In this regard, the Adaptive Implementers and Changing Pragmatists clearly pointed to the need for institutions to commit to providing opportunities for continuous on-the-job learning by creating and supporting communities of practice for benchmarking knowledge gains 
and for sharing effective efficiencies in practice. This need is especially pressing. It reflects the basic socio-semiotic stances of Fullan (2007, p. 153) and of Lave and Wenger (1991, p. 98). The process of sharing information, insights and advice relevant to learners' existing learning issues could help lecturers negotiate the best ways to implement change in student assessment for effective practice.

A fourth implication of the findings from the present investigation points to the imperative of MOET needing to provide substantial investment in resources, facilities and incentives to create teaching environments conducive to effective learning and student assessment. The adverse impact of limited resources on the quality of teaching and learning in Vietnam has been widely recognised (see, for example, Hayden and Lam Quang Thiep, 2010; Nguyen Thi Hong Tham, 2013; Le Thi Kim Anh and Hayden, 2017). These circumstances were instrumental in persuading many of the Changing Pragmatists to not embark on changes in their student assessment practices. For many of these participants, large class sizes, limited resources and the need to devote spare time to earning income meant that it was easier to rely on examination-based summative assessments. The question of finding additional resources, and of providing resource-related incentives, is, however, challenging in the context of Vietnam, where budgets for universities are extremely limited, even though aspirations for global parity remain high and provide aspirational motivation for all academic staff members.

No less important is a fifth implication, that is, concerning accountability as the cornerstone in change management. There is a need for what Fullan $(2010$, p. 66) refers to as "intelligent accountability". Many Adaptive Implementers reported a significant gap in the level of trust amongst lecturers. While they worked very hard to change student assessment practices, others merely did whatever was the minimum required to fulfil their responsibilities. Clearly not all lecturers enjoy a work environment in which those who make more of an effort are neither acknowledged nor rewarded. At present, the accountability framework focuses simply upon the distribution of grades for a unit, regardless of how these grade distributions have been achieved. There is much to be done in terms of developing a targeted monitoring and evaluation capacity in the implementation of assessment and grading practices. Maughan, Teeman, and Wilson (2012) argued that careful monitoring informs decision making at all levels of a system, provides an analysis of ongoing needs, and builds trust as well as understanding within a community. Such a development is essential for higher education institutions in Vietnam.

The participants' comments reveal a general lack of communication among lecturers, and between lecturers and academic managers, about improving the quality of student assessment practices at the site institutions. The theory of complex adaptive systems (Stacey, 1995) points emphatically to the critical importance of communication in allowing differences and dialogues to act as drivers for change. Fullan (1999) further recommends treating resistance as an essential driver of change, arguing that dissimilar ideas and perspectives enable members to work together to address complex problems.

An appreciation among institutional and departmental leaders is needed, therefore, regarding the importance of creating institutional cultures where teaching staff members can interact, selforganise and develop new patterns of behavior to achieve better, more effective student learning outcomes. As Nguyen Phuong Mai, Terlouw, and Pilot (2005) observed, though, the cultural focus of social relations in Vietnam tends to be upon maintaining harmony and avoiding conflict, which runs counter to a culture of vigorous debate and healthy critique that results in new forms of social equilibrium. However, it is not necessarily so dire. A culture of leadership that is concerned more with evaluating different perspectives than with issuing orders based on traditional allegiances would make significant strides forward.

Belief and commitment are critically important to reform in the way student assessment, and in turn student learning, is conducted in the setting of teacher training universities in Vietnam. Fullan's (2007, p. 36) basic argument that beliefs and understanding are fundamental to lasting educational change is highly relevant to this context. The underlying principles of formative, standards-based assessment, and the assumptions about the nature of quality in a learner-centred learning environment that underpin these principles, are potentially confronting in the context of 
higher education in Vietnam. The Defending Denialists were in many respects the defenders of the status quo, which is based on traditional values and beliefs. Attempts to change student assessment practices in teacher training universities will need to overcome a strong tendency for the system at large to see norm-referenced examinations as being the Confucian norm.

\section{Conclusion}

This investigation has pointed to the many challenges facing efforts to embed a 'learning culture', including the adoption of standards-based and formative approaches to student assessment in the higher education system in Vietnam. The Adaptive Implementers comprise a category of reformers within the system, but they are as yet a minority group. Their size and impact would increase if those classified as Changing Pragmatists could be provided with the encouragement, training and reward for joining them in reforming approaches to student assessment. The Defending Denialists represented the status quo, and may well be representative of most academic staff members in Vietnam. Achieving change amongst this group will require firm systemic leadership and policy guidance, increased opportunities for appropriate professional development, a monitoring and evaluation framework that accentuates the need for accountability and transparency, and whole-ofinstitution commitments to change, which higher education systems such as the United Kingdom, the United States, Australia and others have managed through system-wide protocols and rewards for good teaching.

This investigation has reported findings consistent with those recently reported by Ho Thi Nhat (2015), who showed that changes occurring at a policy level in Vietnam are likely to be ineffective if not sustained by a supportive institutional environment for teaching and learning, a focus on training, and a high level of participation by faculties in the adoption of change. Adaptive change is complex but necessary, and the theory of complex adaptive systems suggests that the results of change are often unpredictable. However, without change in student assessment practices in higher education institutions in Vietnam, it seems unlikely that Vietnam will develop a 'learning culture' in these institutions, thereby missing the opportunity to achieve comparability with 'world-class' standards in teaching and learning.

\section{References}

Biggs, J. (1996). Enhancing teaching through constructive alignment. Higher Education, 32(3), pp. 347-364.

Biggs, J. and Collis, K. F. (1982). Evaluating the Quality of Learning: The Solo Taxonomy. New York: Academic Press.

Biggs, J. and Tang, C. (2007). Teaching for Quality Learning at University ( ${ }^{\text {rd }}$ ed.). Berkshire: UK Open University Press.

Black, P. and Wiliam, D. (1998a). Assessment and classroom learning. Assessment in Education: Principles, Policy \& Practice, 5(1), pp. 7-75.

Black, P. and Wiliam, D. (1998b). Inside the Black Box: Raising Standards through Classroom Assessment. London: School of Education, King's College.

Fullan, M. (1999). Change Forces:The Sequel. London: Falmer Press.

Fullan, M. (2001). Leading in a Culture of Change. San Francisco: Jossey-Bass.

Fullan, M. (2007). The New Meaning of Educational Change (4th ed.). New York: Teachers Colleges, Columbia University.

Fullan, M. (2010). All Systems Go: The Change Imperative for Whole System Reform. Thousand Oaks: Corwin Press.

Fullan, M. (2011). Choosing the Wrong Drivers for Whole System Reform. Melbourne: Centre for Strategic Education Melbourne. 
Fullan, M., Cuttress, C. and Kilcher, A. (2005). Eight forces for leaders of change. Journal of Staff Development, 26(4), pp. 54-59.

Glaser, B. G. and Strauss, A. L. (1967). The Discovery of Grounded Theory: Strategies for Qualitative Research. New York: Aldine de Gruyter.

Goldenberg, C. and Gallimore, R. (1991). Changing teaching takes more than a one-shot workshop. Educational Leadership, 49(3), pp. 69-72.

Hayden, M. and Lam Quang Thiep. (2010). Vietnam's higher education system. In G. Harman, M. Hayden and Pham Thanh Nghi (Eds.), Reforming Higher Education in Vietnam: Challenges and Priorities. London, New York: Springer, pp. 15-30.

Ho Thi Nhat. (2015). An Exploratory Investigation of the Practice of Assessment for Learning in Vietnamese Higher Education: Three Case Studies of Lecturers' Practice. Unpublished PhD thesis: Queensland University of Technology.

Institute for Educational Research. (2005). Foreword. Paper presented at the scientific conference on "The role of the examination and assessment activities in educational reform in Vietnam", The Institute for Educational Research, Ho Chi Minh City Univesity of Pedagogy.

Kane, M. B. and Khattri, N. (1995). Assessment reform. Phi Delta Kappan, 77(1), pp. 30-33.

Lave, J. and Wenger, E. (1991). Situated Learning: Legitimate Peripheral Participation. Cambridge: Cambridge University Press.

Le Thi Kim Anh, and Hayden, M. (2017). The road ahead for the higher education system in Vietnam. Journal of International and Comparative Education, 6(1), pp. 77- 89.

Lincoln, Y. S. and Guba, E. G. (1985). Naturalistic Inquiry. Beverly Hills, CA: Sage.

Luong, G. (2016). Achieving Change in Student Assessment in Vietnamese Teacher Training Institutions. Unpublished PhD thesis. Southern Cross University.

Marton, F., Hounsell, D. and Entwistle, N. (1984). The Experience of Learning: Implications for Teaching and Studying in Higher Education. Edinburgh: Scottish Academic Press.

Maughan, S., Teeman, D. and Wilson, R. (2012). What Leads to Positive Change in Teaching Practice? Slough: National Foundation for Educational Research.

Ministry of Education and Training (MOET). (2007). Decision No. 43/2007/QĐ-BGD\&DT: Regulation of University and College Training According to the Credit System.

Morgan, C., Dunn, L., Parry, S. and O’Reilly, M. (2004). The Student Assessment Handbook: New Directions in Traditional \& Online Learning. London: RoutledgeFalmer.

Mouza, C. (2002). Learning to teach with new technology: Implications for professional development. Journal of Research on Technology in Education, 35(2), pp. 272-289.

Nguyen Phuong Mai, Terlouw, C. and Pilot, A. (2005). Cooperative learning vs Confucian heritage culture's collectivism: Confrontation to reveal some cultural conflicts and mismatch. Asia Europe Journal, 3(3), pp. 403-419.

Nguyen Thi Hong Tham. (2013). Assessing Student Learning in Selected Social Sciences and Humanities Undergraduate Programmes at Universities in the UK and Vietnam: A Comparative Case Study. Unpublished PhD thesis: University of Nottingham.

Patton, M. Q. (2002). Qualitative Research and Evaluation Methods ( $3^{\text {rd }}$ ed.). Thousand Oaks: Sage. Rowntree, D. (1977). Assessing Students: How Shall We Know Them? London: Harper \& Row Ltd.

Shepard, L. A. (2000). The role of classroom assessment in teaching and learning. CSE Technical Report 517. Los Angeles: Center for Research on Education, Diversity and Excellence.

Spradley, J. P. (1979). The Ethnographic Interview. New York: Holt, Rinehart and Winston.

Stacey, R. D. (1995). The science of complexity: An alternative perspective for strategic change processes. Strategic Management Journal, 16(6), pp. 477-495.

Stacey, R. D. (1996). Complexity and Creativity in Organizations. San Francisco: Berrett-Koehler.

Stacey, R. D. (2007). Strategic Management and Organisational Dynamics: The Challenge of Complexity to Ways of Thinking about Organisations. Harlow/ Sydney: Financial Times Prentice Hall. 
Tosey, P. (2002). Teaching on the Edge of Chaos. Complexity Theory, Learning Systems and Enhancement. Working Paper, University of Surrey.

Tran Thi Tuyet. (2013). Limitation on the development of skills in higher education in Vietnam. Higher Education, 65 (5), pp. 631-644.

Wenger, E. (1998a). Communities of Practice: Learning, Meaning, and Identity. Cambridge: Cambridge University Press.

Wenger, E. (1998b). Communities of practice: Learning as a social system. Systems Thinker, 9(5), pp. 2-3.

Wenger, E., McDermott, R. A. and Snyder, W. (2002). Cultivating Communities of Practice: A Guide to Managing Knowledge. Boston: Harvard Business School Press.

Wenger, E. and Snyder, W. M. (2000). Communities of practice: The organizational frontier. Harvard Business Review, 78(1), pp. 139-146.

\section{Appendix A}

\section{Interview Schedule}

1. Please tell me how long have you been working in this institution and what role or responsibilities you have regarding teaching and assessment at this institution?

2. What units do you teach currently, and could you please tell me how you assess student learning in each of them?

a. What do you want to assess and how do you do this?

b. How do you grade a group of students?

c. And how often and how do you provide feedback to your students?

(And if the participant was an educational manager: What are the main forms of student assessment in your institution? And what forms of student assessment do you prefer as a manager? Why?)

3. What do you most value, as a lecturer, in student assessment?

a. When implementing student assessment, what are your main assessment purposes?

b. What is your understanding of the teacher's role in the assessment process?

c. What important learning outcomes do you look for?

(And if the participant was an educational manager: As an educational manager, what do you value, most in student assessment? What main outcomes do you expect from your institution's student assessment practices?)

4. In the literature on student assessment, there are many approaches to assessment described. How familiar are you with any of this literature or these models?

5. How are your student assessment practices different from what you did ten years ago? (And if the participant was educational manager: How much do you know about any Government regulations or national protocols for student assessment? And what are your views about them?)

6. If you were to try to improve your assessment tasks, what changes would you make, and why? (And if the participant was educational manager: To what extent do you encourage lecturers to implement these regulations?)

7. When you look around within your School, what student assessment practices do you see where you would like to see change? What concerns you most about student assessment in your School? 
8. What practical difficulties do you face with when you implement student assessment? (And if the participant was educational manager: If an academic staff member does not fully comply with these approaches, explain why this might be.)

9. If you had three wishes for how student assessment practices in your School should change, what would they be? How much ability to affect changes like these in your School do you have? (And if the participant was educational manager: How much influence do you have over assessment and grading practices?)

10. And, if you had three wishes for how to change your own assessment practices, what would they be? How much authority do you have to make these changes yourself?

11. Is there anything else you would like to tell me about student assessment practices in your School? 